\title{
From Reimagining to Repositioning Accountability
}

\author{
Wenny Ho
}

\begin{abstract}
This article contributes to reimagining a 'new generation' of accountability. It draws on country studies and a workshop organised by ActionAid International. The studies highlight the need for further clarifying roles between development actors, the importance of allowing sufficient time for organisational and relational changes and strengthened accountability, the continuing significance of meaningful participation and the need to recognise power in accountability relationships and practices. The author proposes making accountability a central driver in a development actor's theory of change, which would give the organisation a resilient spine as well as flexibility and manoeuvrability. $A$ new relationship between accountability and monitoring and evaluation is also proposed. Such a conceptualisation of accountability provides the clarity and simplicity needed to leapfrog the myriad initiatives created in response to donor pressures for accountability and the measurement focus that currently grips the development sector.
\end{abstract}

\section{Introduction}

The backdrop of the global economic crisis and the challenges to the development paradigm and donor practices that have accompanied it have meant new pressures for accountability on and within the development system. In this context, rethinking accountability has become an urgent priority for development actors across the system. This article reports on an initiative of ActionAid International (AAI) that was undertaken with support from the IDS Reimagining Development initiative, to rethink accountability within their work. The aim of this initiative was to restore accountability as an inspiring and guiding concept and practice within AAI's work, and to generate wider lessons about accountability and international NGOs in development.

For AAI, the initiative came at an important moment of organisational stocktaking and strategising for the future. As groundwork for the initiative, case studies were undertaken in five countries: Ghana, Kenya, Nepal, Bangladesh and Nigeria, in 2010, with support from AAI's International Secretariat and IDS. This article draws out some general ideas of relevance to the wider development community and enriches these with the author's own research and experiences. It points to a 'new generation' accountability concept and practice, and thereby contributes to efforts to sidestep the measurement-focused trends that currently grip thinking about accountability within development practice.

\subsection{Background to AAl's accountability initiative} Commitment to a just world has long guided AAI's development approach, and accountability has consistently been treated as a central value. Yet AAI was increasingly aware of worrying weaknesses in its accountability practices. A 2007 review of ALPS, 'AAI's organisational model of accountability found that the principles of ALPS were sometimes given less attention than the bureaucratic aspects of accountable practice. Discussions convened by AAI's GEO to explore AAI's accountability concept with Secretariat staff similarly found, despite strong commitment to accountability, the concept was neither welldocumented, nor understood in a coherent way, leading to a generally weak accountable practice. These reflections within ActionAid gave rise to several key questions about what accountability means for INGO practice, such as:

- What does it mean to be accountable in international advocacy and campaigns? To whom are actors to be accountable, how, and for what? 
- How can demand-side accountability from rights-holders in movements be strengthened? What is the potential for more powerful mandatory mechanisms?

- What accountability mechanisms and processes have and can be developed to support a more effectively 'political' and rights-specific approach?

- How should accountability relationships differ for different kinds of partnerships?

- How can donor-generated demands for outcome reporting, logical frameworks and results-based management be managed to contribute to, rather than detract from, AAI's strategic accountability to rights-holders?

Other factors that signal the need for deeper reflection about AAI's understanding of and operationalisation of accountability in this fastchanging context include a rethinking of AAI's perception of the state, the impact of its decision to increase income from official donor agencies, and strategies for wider accountability, beyond local and specific constituencies (Hargreaves 2009).

The 'Rethinking Accountability' initiative was a response to the demonstrated need for an improved, updated concept of accountability.

\section{Ideas from the field: case studies on accountability}

Case studies were undertaken in Ghana, Kenya, Nepal, Bangladesh and Nigeria, by teams composed of AAI country staff and development partners. The case studies were designed to address the following questions:

1 How has the accountability concept and practice being used by ActionAid evolved in relation to its current rights agenda and strategy?

2 What needs to change in order for the concept and practice of accountability to more fully support the organisation's political and strategic direction?

Within those broader questions, each team examined a specific practice or issue related to accountability to poor and excluded people. While the methodology used in each country differed, all used participatory tools and interviewing techniques. While the short timeframe meant the case studies were necessarily limited in scope, a number of interesting findings that shed light on the concept and practice of accountability emerged. In Ghana and Kenya, the case studies focused on accountability issues related to direct relationships with poor and excluded people, while in Bangladesh, Nigeria and Nepal, the focus was on accountability issues related to working with higher-level constituencies such as federations of the poor, alliances, coalitions and social movements.

Starting with the core of AAI's understanding of accountability, ActionAid Ghana (AA-G)

explored the degree to which it walks the talk at the level of its values. The main aim was to obtain frank critical feedback that generally does not emerge during its participatory review and reflection activities. The case focused on generating a thorough understanding of how the communities perceived AA-G's core values, followed by a ranking exercise to analyse and document their perceptions of the extent to which AA-G adheres to each value. The idea was to expand the agency of communities to hold AA-G to account. AA-G intends to take this process to more communities and to further develop the methodology.

ActionAid Kenya (AA-K) examined the effects for accountability of posting local project budgets on transparency boards. The case study discovered that although the practice succeeded in enhancing its credibility with donors, and other actors have replicated the practice, it had not led to any instances of communities questioning budgets. A lesson was that the format needs to be accessible and the content of the information to be posted should be agreed with communities; improved transparency through the use of these boards did not on its own lead to stronger accountability. AA-K now plans to experiment with a combination of tools that have shown their usefulness in holding government to account, such as Elbag and social audits.

Looking back on ten years of working with disabled people, ActionAid Bangladesh (AA-B) and its partner distilled lessons for a wider audience. The case study identified impacts of culture on people's capacities to claim accountability from government, and their willingness to challenge the status quo, demonstrating that capacity building does not 
automatically enable disabled people to demand accountability. A conclusion was the need to build people's confidence in claiming accountability and working with partners to de-stigmatise disability. A second conclusion was that there is a strong and mutually reinforcing link between rights-holders' capabilities to claim accountability from government and their ability to claim accountability from AA-B. The case study demonstrated the need to work to increase accountability simultaneously at different levels, combining direct activities with disabled people with campaign work, as well as the creation of social safety-nets to help overcome resistance.

ActionAid Nigeria (AA-Ng) examined how two national, ActionAid-founded HIV alliances managed their accountability to the communities they work with and their relationship with AA-Ng. A number of issues that emerged resonated with findings from the Bangladesh and Nepal cases. Similar to Bangladesh, contextual factors greatly influenced the effectiveness of accountability mechanisms. For example, the level of corruption in Nigeria is an important influence on the financial accountability of coalitions and networks. As was found with support to social movements in Nepal, support to alliances in Nigeria was giving rise to demands for clarity in relation to evolving roles. Coalitions and networks are in general weakly accountable to rights-holders. This means that while partners need space to develop their identity and autonomy, demand-side measures to strengthen demands for accountability by communities need attention; as a consequence, support to coalitions and networks is to be complemented with work at community level.

Together with its long-term partner, ActionAid Nepal (AA-N) examined accountability issues in relation to a social movement, the National Land Rights Forum. The case study found that strengthening the movement's internal mechanisms was crucial to its success. For example, processes of analysing and reflecting about power relations, in combination with participatory decision mechanisms enhanced accountability within the movement itself. The value of strengthening the accountability mechanisms evolved by the movement itself rather than imposing external ones is another lesson. In the same spirit, the emphasis placed by the partner on supporting the movement to raise their own funds allowed them to evolve their own course rather than succumb to pressures for 'upwards' accountability to AAI. Flexible funding instruments played a key role in making this possible. The case study also found that enabling the movement to mature and grow requires supporting INGOs to be sensitive to the fine line between facilitation and imposition. A crucial factor that has contributed to the building of strength of the social movement has been a continual adjustment of roles of both AA-N and the partner over the long years of working together to allow for and respond to the growing maturity of the movement.

\section{Building from the field}

In August 2010, members from each country team joined the international IASL team at IDS to explore the implications of the different case studies for AAI's accountability concept and practice in its future strategy. Some of the broader issues that emerged from the workshop included the need for greater clarity about the roles and relationships between development actors, in a rapidly changing context; the importance of time, in terms of organisational and relational changes over time, and the time needed to learn and reflect to develop stronger relationships of accountability; the continuing significance of meaningful - not merely formal - participation; and the need to recognise dimensions of power in accountability relationships and practices. Each of these are looked at in turn.

\subsection{Clarity about roles and relationships}

Like other INGOs, AAI provides support to an increasing range of types of organisations and actors across the globe. Yet in its approach to accountability, differences between, for example, AAI's role in relation to community organisations compared with its relationship to networks or coalitions have not to-date been translated systematically into a differentiated strategy with appropriately tailored approaches or methodological instruments. Yet relationships with different types of organisations evidently require different approaches to and forms of accountability. As AAI engages more with umbrella organisations and less formal groups such as social movements, it becomes more pressing to understand its functions and roles in relation to the organisations it works with. Clarifying the changing nature of the relationships between international NGOs and 
their partners is the first step towards rethinking accountability in development practice.

\subsection{Time as a critical resource for stronger accountability}

Understanding the respective roles of different development actors requires an acknowledgement of time as a critical resource in two ways. First, organisational growth over time of people's organisations and partners will be accompanied by a change in responsibilities and the boundaries of each organisation and stakeholder. Accountability should therefore be articulated in a dynamic way, because the way it is expressed and supported effectively changes over time. Second, the reflection and transformative capacity building required to build accountable systems and relationships also need time. The case studies document how applying the same accountability tools and mechanisms without dedicating sufficient time to reflection and participation can lead to mechanistic bureaucratic procedures, rather than to substantively accountable systems. In consequence, the AAI commitment to accountability requires a commitment to ensuring the time is available to enable staff to reflect fully on their commitments and decision-making processes.

\subsection{Participation at the centre}

Although it has been clear for some time that an accountability strategy demands a participatory approach, the case studies show the many obstacles that have to be overcome to build participation into an accountability strategy. Although deep, long-term processes of capacity building through participatory approaches are essential to strengthening accountability, overloaded agendas mean that events that should generate critical and reflective feedback easily turn into tick-box exercises. In consequence, informal gatherings tend to generate more critical reflection than formal participatory exercises. AAI, and no doubt other organisations, will need to free the resources needed to build the ability of the people it works with to hold them accountable. These resources include the space and time for critical reflection, and more transformative forms of support, beyond formal, standard courses and training events.

A final consideration is that accountability tools alone are not sufficient, especially because commitment to accountability requires taking into consideration the need to address power relations. This in turn requires support to staff, partners and people to handle conflict situations constructively as learning situations. All this necessitates organisational resources (time and staff). Commitment to a participatory approach to achieve accountability to the people therefore obliges AAI to boldly overcome the clash with the current linear do-mode and reduce workloads to allow for flexibility in responding, and agility in a day-to-day practice of reflection.

For those who may not be familiar with AAI, its present reflections on what accountability means in development practice are part of a more enduring effort to strengthen accountability within its own organisational arrangements. In 2003, AAI decided to deepen its commitment to accountability by becoming an international federal organisation - a crucial step in its transformation from a transnational British funding NGO to a global alliance 'equally owned and governed by organisations in the North and South' (Singh et al. 2009: 15). Former country programmes are on the way to becoming nationally governed, autonomous entities. Nationally, the new structure has two bodies, an assembly and a board. This structure is repeated at the international level. AAI intends to deepen its accountability in three ways: by involving stakeholders in the national and international governance structure, by ensuring mutual accountability between the two levels, and by improving and strengthening AAI's own governance standards and practices.

The two other objectives of its internationalisation process are to strengthen its effectiveness in fighting poverty and injustice by increasing the relevance of its work, and its credibility and impact at local, national and international levels, and by democratising how it governs itself with real powersharing and genuinely joint decision-making.

Feedback indicates a range of early gains of the internationalisation process for ActionAid. These include access to a greater diversity of insights, stronger mechanisms for accountability, especially at the national level, and overall, increased credibility for AAI. Although there remain many challenges (Ovonji-Odida and Nickson Ogwal 2009), the devolution of decisionmaking over strategic issues, including funding, is unique in the world of development actors. 


\section{A leap to the future: repositioning accountability in the work of AAI and beyond}

This closing section takes further the reflections about the way accountability was being conceptualised and acted on in ActionAid. Based on this and previous work in this area, the author offers her own analysis of how accountability could usefully and flexibly be incorporated into the heart of the organisation's work. She proposes an approach that would make accountability central to the core of the theory of change, enable a responsive approach to complex situations, to learn about the effects of stronger accountability, and treat the effects on the agency of the poor as the litmus test of their effectiveness.

A strong commitment to accountability led AAI to place it central to its organisational values, from which it has guided the development of key organisational processes and procedures. One of the lessons from the 'Rethinking Accountability' initiative has been a need to bring accountability down from the pedestal of high values, to the ground where it needs to become part of AAI's daily work. Accountability should be understood less as a value than as the kernel of AAI's theory of change. That is, accountability is the core of the theory of change: that being accountable changes relationships of power by strengthening the agency of poor and excluded people to demand accountability from duty-bearers, in claiming their rights and justice (T. Raj 2010, pers comm). The question of what AAI is accountable for is thus linked to the desired social change, articulating accountability as a driver of social change but how this translates into concrete results depends greatly on the context.

A second reflection is about the value of a theory of change centred on accountability. Under conditions of increasing complexity and diversity, successful NGOs rely for guidance on a combination of a high-level theory of change, with assumptions derived from that theory about the contributions of their interventions, to key changes (Ho, forthcoming). These interventions are not precisely defined from the outset; this flexibility to respond to context and circumstance forces the NGO to have its hands constantly on the wheel; each step of implementing the intervention requires its full attention. Practices such as the use of these open protean frameworks to guide development action have a number of distinct advantages. They allow the NGO to intertwine direction with the flexibility to alter and adapt.

It is possible to see how an open framework of this kind could be mapped onto AAI's concept of accountability in an effective organisational management tool. This would make accountability the key intervention placed at the heart of its theory of change, giving AAI a nonnegotiable, resilient spine, as well as the flexibility and manoeuvrability needed in complex settings. Making accountability central to its theory of how it brings about change would enable AAI to interactively shape and be shaped by its various accountability relationships and contexts, and to develop deeper roots in the cultures and contexts where it is active, while maintaining a coherent core direction.

The challenge of demonstrating conclusively that stronger accountability in development interventions produces better outcomes (J. Gaventa 2010, pers comm) is particularly pertinent for AAI, which perceives accountability to be at the centre of its values and development approach. A third reflection from the reimagining exercise has been to do with evidence. Navigating accountability in relation to monitoring and evaluation has been confusing in recent years, and many heated discussions have resulted. There is a need for clarity in these discussions, and an alternative view of the relationship between accountability and monitoring and evaluation is proposed here.

Following through on the vision of accountability to the poor as a key driver in the theory of change requires it to be judged by the degree to which it strengthens people's agency. Complex situations will then demand the process of making continual judgements about whether the agency of the poor will be positively influenced, and whether the agency of the poor has been positively influenced. Answering these simple questions requires a continuous, interactive and collective process of thinking and sense-making. Reflection about possible answers could range across the institutional levels, from international, regional, national or local, and to the wide range of stakeholders with whom AAI works. In this way, accountability would function as both a compass and a litmus test, grounded in 'what works in the field' (Ho 2007). The questions are simple enough to stay clear and focused in people's 
minds, yet also offer flexibility to tease out answers in diverse situations. When used capably, they may be supple navigation tools, in support of making choices in a complex world.

By way of concluding thoughts, when reimagining development, a basic requirement is to refuse to be bound by the existing and the

\section{Note}

1 ALPS: Accountability, Learning, Participation and Sharing.

\section{References}

Hargreaves, S. (2009) 'The Politics of Accountability in our Struggles for Rights and Justice', Exchanges 4, March (newsletter of the IASL community): 33-40

Ho, W. (forthcoming) Beyond Resilience: Unravelling the Success of NGOs as Actors in Development, Johannesburg: ActionAid International, South Africa

Ho, W. (2007) 'Sensemaking in Turbulent Times: Everyday Strategic Changing by Indian current. Reimagining accountability entails leapfrogging the myriad initiatives created in response to increasing donor pressures for accountability, and to boldly propose a visionary perspective in their stead. We need to regroup the passionate and nurture the spark of humanity in development. Clarity and simplicity will create the space that spark requires.

NGDOs', PhD dissertation, University of Amsterdam

Ovonji-Odida, I. and Nickson Ogwal, H. (2009) 'Deepening Accountability Through Nationalisation: The Ugandan Experience', Exchanges 4, March (newsletter of the IASL community): 25-9

Singh, R.; Oguta, J. and Costa, D. (2009) 'Internationalisation, an Organisational Transformation', Exchanges 4, March (newsletter of the IASL community): 14-19 